\title{
The Theory Of Planned Behaviour And The Impact Of Past Behaviour
}

\author{
Lutz Sommer, Albstadt-Sigmaringen University, Germany
}

\begin{abstract}
The Theory of Planned Behaviour (TPB) has since its development some 20 years ago proved to be a powerful approach to explain human behaviour. It has been successfully applied to a wide range of behaviours. Interestingly, it is in particular complex behaviour such as managerial decision making which saw only a few attempts to use TPB. This is in particular true for company internationalisation. While the main elements of the theory are generally accepted, it has been suggested at many occasions that the model would benefit by the inclusion of more constructs in terms of explanatory quality. Among the elements proposed, Past Behaviour is of particular importance. Although being vividly discussed, researchers did not come to a definitive judgement on whether or not the construct really should be integrated as an independent factor. The paper at hand adresses these issues by developping a framework for an extended TPB which should be relevant in particular for complex behaviours such as International Entrepreneurship. It is based on an extensive literature review which identifies two main lines of research in terms of Past Behaviour. Using a decomposition approach to integrate Past Behaviour, the shortcomings of earlier approaches are avoided. The framework features a second contribution by explicitly modelling information processing modes, which are proposed to influence development of intentions.
\end{abstract}

Keywords: Theory of Planned Behaviour; Intention; Past Behavoir; Internationalisation; Experience; International Entrepreneurship

\section{INTRODUCTION}

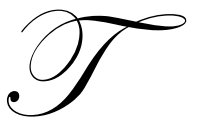

he theory of planned behaviour (TPB) has been applied to a wide range of behaviours in order to better understand which individuals behave in which way. It is one of the best-supported social psychological theories with respect to predicting human behaviour. Central premise is that behavioural decisions are the result of a reasoned process in which the behaviour is influenced by attitudes, norms and perceived behaviour control ( Smith et al., 2007). These constructs influence the behaviour primarily through the impact on behavioural intention. The relation between intention and behaviour could be described as follows (Sheeran 2002, p. 1 ): "People do what they intend to do and do not do what they do not intend." The TPB is an extension of the theory of reasoned action (Fishbein / Ajzen, 1975) in that the construct Perceived Behavioural Control (PBC) has been added. PBC as additional construct could solve the problem of the theory of reasoned action in terms of explaining behaviours in which the actor does not have full volitional control (Fen / Shabruddin, 2008 ).

In the last two decades of research both theories have provided support for the ability to predict a wide range of behaviours. They have been used in prediction of health-related behaviour, recycling and driving behaviour. The predictive power also has been demonstrated in the consumer (Smith et al., 2007) and entrepreneurship domain ( Krueger / Carsrud, 1993). However, there are a lot of field where TPB has been used at a very few occasions only. One of them is company internationalisation. Several theories have been developed to explain cross-border business activities. One of particular relevance is International Entrepreneurship, as this theory explicitly takes into consideration one factor which is of crucial importance especially in the internationalisation of Small and Medium-sized Enterprises (SME): the decision maker (Miesenböck, 1988; Ruzzier et al., 2006). While this research stream which is called International Entrepreneurship (IE) seems to be a promising research avenue (McDougall/Oviatt, 2000), several facets clearly requires further research - one of them is cognition. This field is 
from a TPB perspective a very interesting one, as it represents a rather complex behaviour which possibly requires additional elements as compared to the basic model.

According to Sheeran (2002), at least two questions require further discussion, i.e. how well intentions predict behaviour and what determines how well intentions predict the behaviour. The findings of a meta-analysis ( Sheeran / Orbell, 1998) confirmed a correlation between $r=0.40$ to $r=0.82$ and that intentions account on average for $28 \%\left(R^{2}=0,28\right)$ of the variance in behaviour. In other words, there is gap of $72 \%$ which still is unexplained. Therefore, TPB can be described as incomplete model. Consequently many researchers have tried to increase the proportion of explained variance by including additional variables, e.g. Past Behaviour ( Wong / Mullan, 2009, pp. 491). Unfortunately, Past Behaviour is one of the most critical constructs in TPB and has induced an intense discussion in literature. Thus, the role it really plays in predicting future behaviour - and if so, how the influence works - is anything but clear.

Based on these considerations, this paper aims at clarifying the following aspects:

- Which role does Past Behaviour plays in the framework of TPB?

- How should Past Behaviour be modelled in order increase TPB's predictive strength?

- Do specific information processing modes represent a useful extension of TPB?

This paper therefore will develop a conceptual framework integrating Past Behaviour. To do so, TPB is linked to information processing theory and in particular to Cognitive Style Theory, which is widely recognized as an important factor in determining individual behaviour (Sadler-Smith/Badger, 1998). It is "a higher-order heuristic that individuals employ when they approach, frame, and solve problems" (Brigham et al., 2007, p. 31).

This paper proceeds as follows. In the next section, a brief overview of TPB is presented while in section 3 Past Behaviour is discussed. In section 4 relevant information processing modes are reviewed and analyzed for relevance in the context of this paper. A conceptual framework - comprising an extended version of TPB - is presented in section 5. The last section concludes the ideas and presents avenues for future research.

\section{THEORY OF PLANNED BEHAVIOUR (TPB) - A BRIEF OVERVIEW}

\subsection{Fundamentals}

Human behaviour is guided by different subjective probabilities (e.g. Fishbein/Ajzen, 1975), that means beliefs about the consequences of the behaviour, beliefs about the normative expectations of other people and beliefs about the presence of factors which may facilitate or impede performance of the behaviour. Beliefs are based on a wide range of background factors. In their aggregates, behavioural beliefs produce attitude towards behaviour, normative beliefs result in subjective norms and control beliefs generate perceived behaviour control. The combination of all these elements leads to the formation of a behavioural intention (Ajzen 2002, p. 107). Behavioural intention could be described as "... instructions that people give to themselves to behave in certain way" (Triandis 1980, p. 203). In other words, intention represents the motivation of an individual's conscious plan to exert effort to perform the behaviour. Intention could be understood as an immediate antecedent to behaviour ( Ajzen 2002, p. 107). Figure 1 presents an overview of the interplay between the so-called background factors, beliefs, aggregates, intention and behaviour ( Ajzen 2005, p. 135):

\subsection{Review}

Tests of TPB have provided evidence for the predictive validity of intentions (Chatzisarantis et al., 2007). Numerous meta-analytic reviews, e.g. with regard to social behaviour (Armitage / Conner, 2001) or health behaviour (Hagger et al., 2002) have confirmed this relationship. Also a meta-analysis of metal-analyses confirmed the usability of the TPB in general, but the question arises whether an explained variance of $28 \%$ in behaviour is good enough as about $72 \%$ remain unexplained (Sheeran 2002, p. 4). Hence, what determines how well intentions predict behaviour? This consideration leads to two different aspects: first, which conditions generally influence the predictive power of TPB; second, what are concrete determinants of intentions as well as behaviour beyond the elements of the standard model. 


\begin{tabular}{l} 
Background Factors \\
$\underline{\text { Personal }}$ General attitudes, \\
Personality traits, \\
Values, Emotions, \\
Intelligence \\
Social \\
Age, Gender, Race, \\
Ethnicity, Education, \\
Religion \\
Information \\
Experience, \\
Knowledge, \\
Media Exposure \\
\hline
\end{tabular}

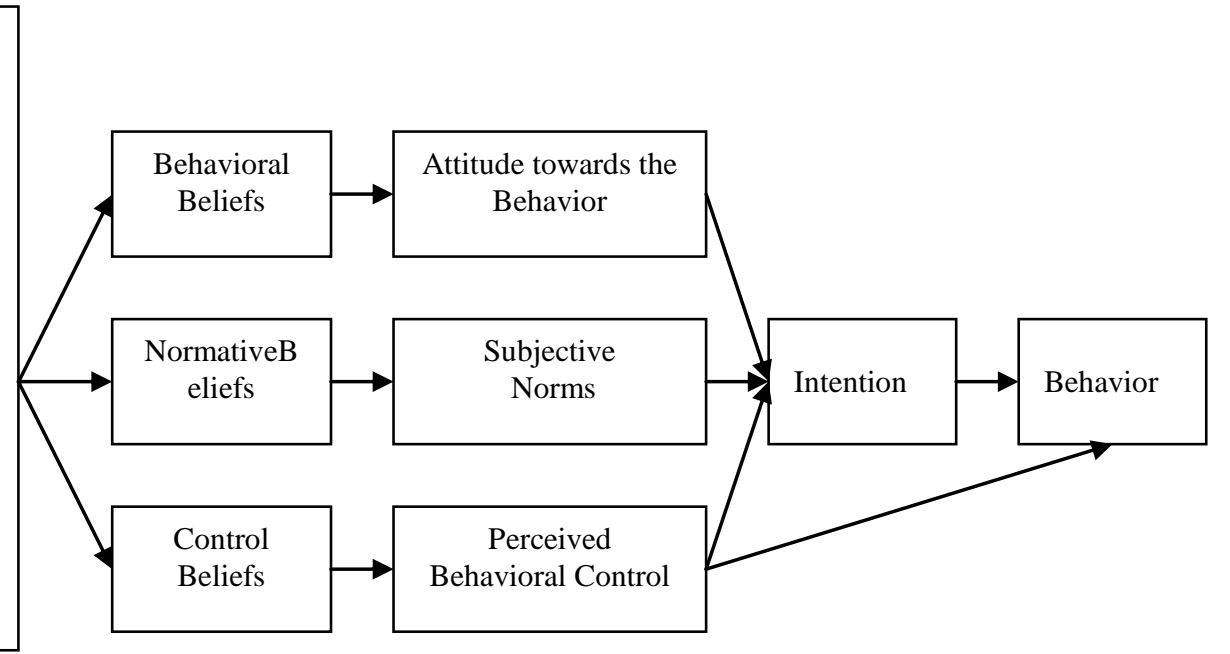

Figure 1: Theory of Planned Behaviour Source: Ajzen (2005), p. 135

\subsubsection{Factors influencing TPB's predictive power}

Sheeran considers the following aspects as being relevant for a general review (Sheeran 2002, pp. 9-24):

a) Behaviour Type: The type of behaviour influences the degree of intention-behaviour consistency. Findings confirmed that intentions are superior predictors of single actions in comparsion to a goal (an outcome of a variety of single actions). Therefore, it could be concluded that a person must have a relevant amount of control (e.g. by control factors like knowledge, resources, opportunity) over performing the behaviour otherwise the intention is not translated into action. Ajzen answered this research question by the integration of perceived behaviour control as a new determinant. He argues that the perception of control is an accurate reflection of actual control (Ajzen, 1991), but is assumption is discussed controversially. Hence, TPB contains two elements influencing behaviour directly: intention and perceived behavioural control. Indeed, PBC could improve explained variance of behaviours where the individual does not have full volitional control. Still, the question arises whether or not further constructs have similar impact.

b) Intention Type: Warshaw and Davis (1985) discussed the possibility of relevant distinction between behavioural intentions and behavioural expectation. Findings to confirm this assumption are still not available. Regarding the concept of implementation intention (Gollwitzer, 1993), significant results have been obtained by several researchers. Findings have shown that implementation intention could increase the likelihood of performing behaviour and further the speed of behaviour initiation. The idea of implementation intentions is based on the Rubicon model of action phases ( Heckhausen, 1991; Gollwitzer, 1996 ). It suggestes a distinction between motivational phase and volition phase. The Rubicon Model based on four phases: (1) the predecisional phase could be described as deliberating about pros and cons of wishes and desires by assessing the desirability and the question of feasibility; (2) the postdecisional phase used to plan the implementation of the chosen goal ( planned by deciding on when, where and how) ; (3) the actional phase is characterized by progress toward the goal via initiating goaldirected behaviours; (4) postactional phase could be described as evaluation of the achieved outcomes of the goaldirected behaviour (Achtziger / Gollwitzer 2007, p. 769).

In the above mentioned first phase the person develops an intention to change something, in the volitional one the "intended behaviour must be planned, initiated and maintained ..." (Sniehotta et al., 2005, p. 145) where action planning, self-efficacy and action control could play an important role. Gollwitzer named such a detailed action planning "implementation intentions" (Sniehotta et al., 2005, pp. 145 - 146). Figure 2 illustrates the model ( Heckhausen, 1999, p. 114): 


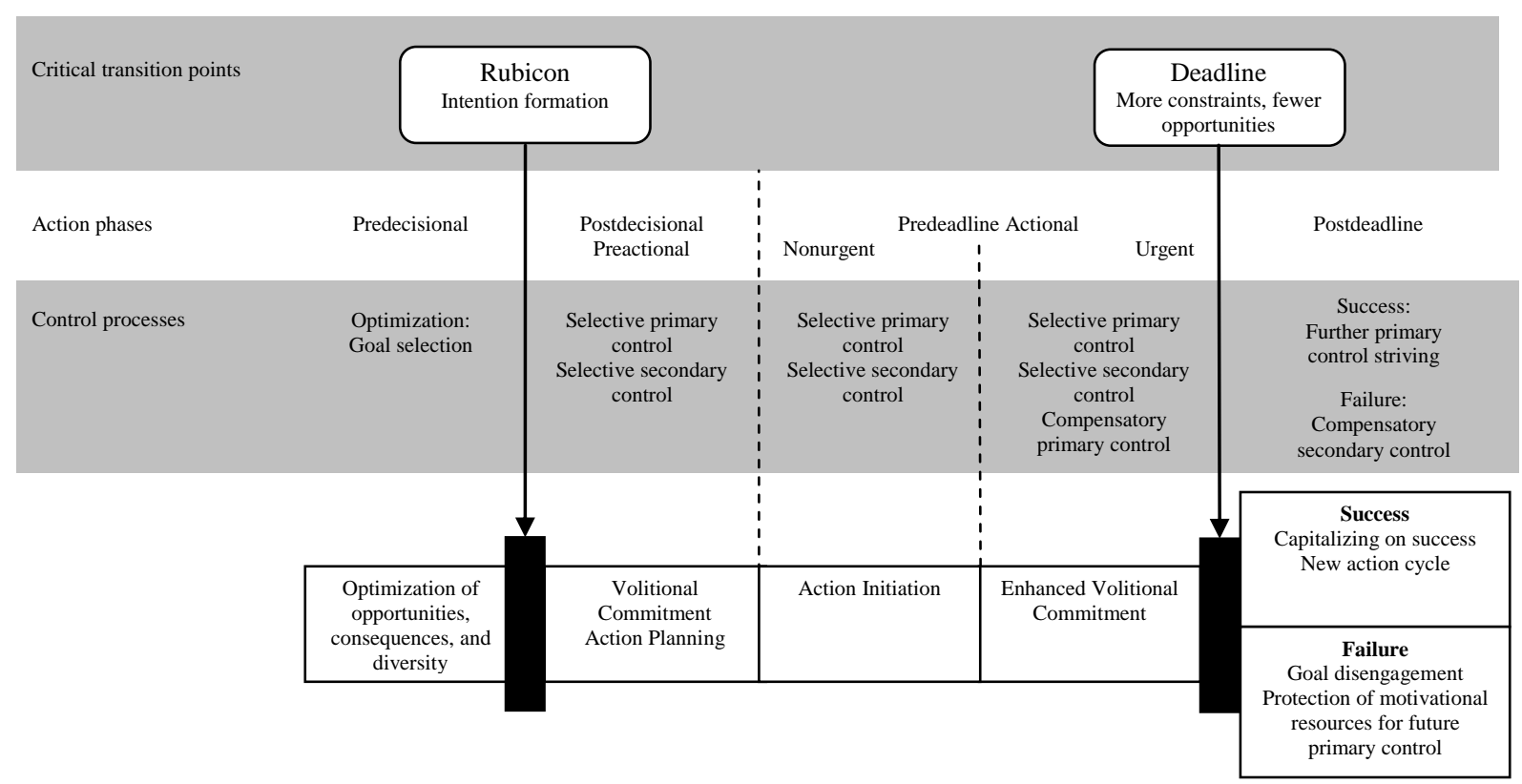

Figure 2: Rubicon Model of Action Phases

Source: Heckhausen (1999), p. 114

In detail, according to Gollwitzer the predecisional phase ends with forming a goal intention, which is in line with Ajzen's view of intention formation. The implementation phase includes the planning and deals with the question, when, where and how to act based on the goal intention. These plans are assumed to mediate the goal intention-behaviour relation (Sniehotta et al., 2005; Baron / Kenny, 1986). Gollwitzer called such plans - as mentioned before - implementation intentions. Such an implementation intention with an executing character is "closer to behavioural enactment, and therefore proposed to be the immediate determinant of behaviour" (Hooft et al., 2005, pp. 241 - 243).

Hooft and colleagues further argued that "the transition from goal intentions to implementation intentions is more cognitive, the implementation intentions-behaviour transition is more behavioural in nature" (p. 244). They hypothesise that prospective action-state orientation moderates the cognitive part and the procrastination trait moderates the behavioural part. They further expect that the implementation intention mediates the goal intentionbehaviour relation (Hooft et al., 2005, pp. $244-245$ ). Applied to job seeking, support was found only for the mediating role of implementation intention. (Hooft et al., 2005, pp. 252).

c) Properties of Behavioural Intentions: Fundamental idea is that people might have identical scores on an intention scale but differ in the quality of individual motivation. An explanation could be ( Cooke/Sheeran, 2004) that people's intentions possess other properties, e.g. temporal stability, degree of intention formation, attitudinal versus normative control or certainty and accessibility.

d) Personality and Cognitive Variables: Subject of this line of research is on the one hand the personality variables, which involve people's general tendencies to think and behave. Kuhl (1985) has figured out that actionoriented participants are more focussed on actions to reduce the gap between their current and future intended state, whereas state oriented participants more focussed on their current state (intended state) and therefore do not consider alternative actions. Kuhl concluded that action control could be helpful for a better understanding of the intentionbehaviour relationship. On the other hand the effect of particular cognitions on the intention-behaviour relations has been tested. Moderation impact has been found for anticipated regret, self-schemas and conflicting intentions. 


\subsubsection{Determinants of intentions and behaviour}

As can be seen from this brief review, a lot of factors and circumstances are likely to influence predictive strength of TPB. This paragraph now takes a look on those elements which determine behaviour and intention.

- $\quad$ Determinants of Behaviour: According to Theory of Reasoned Action (Fishbein/Ajzen 1975), intentions are the sole determinant of behaviour. The TPB considers perceived behaviour control as a second determinant of human behaviour. Whether that assumption is right or wrong is not as clear as it seems to be. For example Wegner and Wheatley (1999) are doubtful about the idea that intentions cause behaviour. Sheeran (2002) suggests that “ ...behaviour [is] governed either by intentions or by automatic processes. However the assumption is that most human behaviour is governed by autmatic processes rather than by intentions" (p. 25). Furthermore, there is evidence in several studies that past behaviour often predicts future behaviour directly. Some authors argue, that past behaviour would be a better predictor for future behaviour than intention. A recent study confirmed the ongoing interest in the investitgation of past behaviour as possible predictor (Wong / Mullan, 2009, p. 489). Scholars also proposed that “...in domains that facilitated development and execution of habits, past behaviour was a strong predictor and intention relatively weak"'(Ouellette/Wood, 1998, p. 66). Other scholars as well demonstrated the importance of a proper conceptualization of past behaviour (cf. Rhodes / Courneya 2003, p. 57). Sheeran (2002) sums up, that most researchers would agree that "...people sometimes see intentions as causes of their behaviour when intentions are not the cause, and that automatic processes have an important role in understanding behaviour" (Sheeran 2002, p. 26). Aarts and Dijksterhuis (2000) suppose that "...habits are mentally represented as goal-action links, and the formation of implementation intentions [...] may simulate goaldirected automaticity in habits (Aarts/Dijksterhuis, 2000, p. 53; Aarts, 2007, p. 59). This list is not complete, but comprises relevant elements for the present analysis. Besides the direct influence on behaviour, indirect moderating effects between intention and behaviour exist. For example, one line of research tries to find out, whether e.g. procrastination, action-state orientation (Hooft et al., 2005, p. 238) or habits ( Limayem et al., 2003, p. 12) play a moderating role in terms of the intention-behaviourgap. As the focus of this analysis is on investigating the immediate influence of determinants on behaviour, moderating effects could only be partly considered.

- Determinants of Intentions: Based on findings of the meta-analytic review of TPB by Armitage and Conner (2001) it could be argued that on the one hand attitude, subjective norm and perceived behaviour control, subdivided in perceived control over behaviour and self-efficacy, have significant stronger multiple correlation with desire than with intentions or self-prediction or a mixed measure of these intention-variants. On the other hand intentions and self-predictions were stronger predictors of behaviour in relation to desire. Subjective norm is the weakest predictor of intention. High levels of perceived behavioural control were associated with strong relationships between intention and behaviour (Armitage / Conner, 2001, pp. 482-484). In sum, different meta-analyses confirmed the efficacy of TPB and their determinants and recommended to include additional factors such as moral norms to increase the predictive power (Armitage / Conner, 2001, p. 489). Other findings indicate the relevance of past behaviour (Ouellette / Wood, 1998, p. 54; Conner et al., 1999, p. 1699; Knussen et al., 2004, p. 244; Rhodes / Courneya, 2003, p. 64) or perceived need ( Fen / Sabaruddin, 2008, p. 108). Also this list is not complete, but comprises additional determinants which could be necessary for this study.

\subsection{Results}

From this brief overview it becomes clear that TPB basically is a well-founded, sound theory able to explain considerable proportions of intention and behaviour. The relevance of the basic constructs, i.e. attitude, subjective norm, and perceived behavioural control, has been confirmed on many occasions. Still, the discussion on specific facets continues, for example which forms perceived behavioural control may have (self-efficacy, perception of control, and others) or whether future behaviour should be observed or self-reported. Nevertheless, a gap exists between intention and behaviour. Many researchers concluded that some elements are apparently missing in the model and tried to enrich it by the inclusion of further constructs, e.g. moral norms. One of the most interesting - and most intensely discussed - is Past Behaviour. It has been associated with both intention and future behaviour. Looking at the studies in this particular field, it becomes clear that Past Behaviour seems to have several 
forms, in particular Experience with Behaviour (PE), Frequency of Behaviour (FB), and Habits (HB).

\section{PAST BEHAVIOUR}

The role of past behaviour as predictor of intention and future behaviour has attracted attention in literature in the last two decades. With respect to the linkages between past behaviour, intention, and future behaviour, a large body of research is available today. In 2008 and 2009 alone, more than 20 articles dealing with TPB and Past Behaviour have been published, indicating up-to-datedness of the topic. There basically are two lines of research, e.g. the one from Ajzen (1991) who declines the relevance of past behaviour as an extra predictor, or Ouellette and Wood (1998) who vote for the predictive relevance under special circumstances.

\subsection{Definition - Past Behaviour}

Past Behaviour (PB) in general could be understood as actions or reactions of a person in response to external or internal stimuli in the past. In contrast, Habits (HB) could be conceived as a goal-directed automatic behaviour which is mentally represented. Aarts et al. (1998) argue, that “...because of frequent performance in similar situations in the past, these mental representations and the resulting action can be automatically activated by environmental cues" (Aarts et al., 1998, p. 1359). Quellette and Wood (1998) classify behaviour in habitual behaviour and non-habitual behaviour. Habitual behaviour “.. is triggered by environmental events, and its performance requires minimal attention and deliberate control" (Ouellette / Wood, 1998, pp. 56 et seq.). Intentional behaviour is guided by conscious deliberation. Please note that besides habitual and intentional behaviour, there exists a third definition of behaviour called Semiautomatic response pattern (cf. Wegner / Bargh, 1998), which involves controlled and autonomous phases (Ajzen, 2002, pp. 108-109). According to Ajzen (1991, p. 203), Past Behaviour and Habit are anything but the same. Frequency of Behaviour (FB) is a term to describe the repetition of behaviour in the past. It differs from habits because not each behaviour frequently performed has habituated (Ajzen, 2002, pp. 109). Past Experience with Behaviour (PE) represents specific knowledge about the behaviour in question, which is stored in memory (Schank/Abelson, 1995). It could be described as "...important source of information about behavioural control" (Ajzen, 1991, p. 204). It is comparable with habits (Limayem et al., 2003, p. $3)$.

\subsection{Overview - Lines of Research}

For further discussion it seems to make sense to show the differences and similarities between the several lines of research on the one hand and their contributions to research on the other.

"Past Behaviour Does Have Predictive Power" - Research Line

A considerable number of studies have found encouraging results with respect to the influence of Past Behaviour. In the remainder of this section, the most important studies are briefly summarized.

(a) Habit - future Behaviour

Early support for the interplay between habits - as a construct linked to past behaviour - and future behaviour was found by Triandis (1980): a frequently executed behaviour in the past seems to be less guided by intentions. Bargh and Gollwitzer (1994) developed in context of habits the concept of a goal-directed automaticity of habitual behaviours, which is in line with the findings of Triandis. Further support comes from a longitudinal study (Aarts 1996) which too confirmed the positive relation between habits and future behaviour. Further studies, e.g. Bamberg (1996) or Aarts, Verplanken and Knippenberg (1998) also highlighted the importance of habits in context of future behaviour. They stated: “.. when habit was strong intentions, did not predict future behaviour, whereas behaviour was predicted by intentions when habit was weak" (Aarts, 2007, pp. 59-60). Furthermore, Aarts (2007) supposes that under conditions of high frequency and also stability the relation between intention and behaviour was absent. 
An important impulse comes from the research done by Ouellette and Wood (1998). They confirm a relation between past behaviour and intention under special circumstances:"In domains that facilitated development and execution of habits, past behaviour was a strong predictor and intention relatively weak. In domains that did not faciliate habits, past behaviour was a relatively weak direct predictor and intention was quite strong" (Ouellette / Wood, 1998, p. 66). In other words, the predictive power of intentions is high in absence of habits and in specific situations. In line with Bargh (1989) and Logan (1989), Ouellette and Wood (1998) highlighted the context stability (stable context means a constant supporting environment for the performance). They argue: "Behaviours that are well practiced and performed in stable contexts are likely to be repeated because they can be performed quickly, relatively effortlessly, in parallel with other activities, and with minimal or sporadic attention" (Ouellette / Wood, 1998, p. 65). Performing such behaviour does not require a conscious consideration. The authors also argued that habitual behaviours may be directed by goals and intentions, but intentions themselves could become automatic and could furthermore temporarily override under special circumstances the effects of habit (Ouellette / Wood, 1998, pp. 65-66). To sum up, the results indicate that the relation between past behaviour and intention depends on the type of investigated behaviour. Support could be found e.g. by a meta-analysis done by Albarracin et al. (2001). They found consistent with Ouellette and Wood (1998) that unstable contexts such as condom use prevent habituation or automization of the behaviour. Past behaviour therefore is assigned a rather small influence (Albarracin et al., 2001, p. 156).

A new facet in research on the past and future behaviour relation offer Sheeran et al. (1999) by highlighting the relevance of temporal stability of behavioural intentions. In a situation with stable intentions, past behaviour did not offer a significant contribution to predict future behaviour, but if the intention was unstable past behaviour turned out to be the best predictor (Sheeran et al., 1999, p. 731). In conclusion, their findings show that “...temporal stability of behavioural intentions moderates relationships between both intentions and behaviour and between past behaviour and future behaviour" (Sheeran et al., 1999, p. 732).

Also Aarts and Dijksterhuis (2000) found support for the relevance of habits. They sum up that studying the relation among attitudes, intentions and behaviour generated much effort to explain action, but "...it is not the only useful concept for insight into behaviour in general ...We believe that trying to explain what mode of transportation people choose, what they eat, drink, and smoke, and when and how they brush their teeth, habits will prove to be conceptually very useful tools" (Aart / Dijksterhius, 2000, p. 61). This supports the thesis that certain behaviours are entirely or partly automized. Sheeran et al. (2005a) continue the work of Arts and colleagues. Habits seen in their cognitive-motivational view as a goal-dependent automatic behaviour differs from traditional behaviourist view by the goal-dependency. Goal activation acts as a mediator between situation and behaviour in constrast to the behaviourist view (Sheeran et al., 2005a, p. 48). The research findings confirmed the idea "...that when habits are established, simply activating a goal related to the focal behaviour automatically elicits that behaviour" (Sheeran et al., 2005a, p. 47).

Additional support for the importance of habits could be found in the more general explanation of the intention-behaviour relation from Sheeran (2002). He stated that the relation between past behaviour and intention or future behaviour, respectively, requires more attention. In order to decompose the relationship, Sheeran argues based on the work from McBroom and Reid (1992) that "...the relative likelihood of performing a behaviour that one has performed in the past but that one intends not to perform represents the best test of whether habits or intentions better predict behaviour. [...] performance consistent with one's intentions but not with one's past behaviour supports the role of intentions, whereas performance consistent with one's past behaviour but not with one's intentions supports the role of habit when participants have experience with the behaviour" (Sheeran, 2002, p. 28).

A descriptive support for the influence of past experience offers George (2002). He researched the internet purchase decision making processes The research findings confirmed that if "...novice users gain experience, they will make their first internet purchase, and as they become even more experienced, they can be counted on to purchase more often" (George, 2002, p. 170). A more abstract contribution to research provides Rhodes and Courneya (2003). They paid attention to the question of modelling and presented techniques and interpretations of the inclusion of past behaviour in TPB. The outcome of one model is remarkable: “... past behaviour had the largest effect on current intentions along with effects from affective attitude and PBC. Past behaviour also had the largest 
effect on future behaviour along with an effect from intention. Thus, if past behaviour is conceived as an indicator of habit, then habit was found to have an independent influence on current exercise behaviour" (Rhodes / Courneya, 2003, p. 65). A potential moderator effect of habits between intention and behaviour has been discussed by Limayem et al. (2003). These findings are in line with Triandis (1980). Their statement: "As long as a behaviour is new to a person, the person's intention to perform the behaviour clearly influences his or her actual behaviour. However, as the person gains more practice with the behaviour we are likely to observe a shift in importance from intentional towards habitual behaviour" (Limayem et al., 2003, p. 14).

A new aspect to the ongoing discussion was added by Knussen et al. (2004). Based on the standard TPB model, they examined the possible contribution of additional ones like past recycling behaviour, perceived habits of recycling and perceived lack of recycling facilities. The findings confirm a significant independent impact of past recycling behaviour and perveiced habit. Furthermore, there "....was some evidence to suggest that the relationship between past behaviour and intentions was stronger for those with no perceived habit of recycling" (Knussen et al., 2004, p. 244).

Smith et al (2007) integrated not only past behaviour but also self-identity into the model of TPB to improve the predictive power. The results confirmed once again the importance of past behaviour as predictor of intention and as moderator between self-identity and intention (Smith et al., 2007, p. 2741). Chatzisarantis et al. (2007) extended the TPB by perceived autonomy support and past behaviour. As expected, past behaviour predicts intention and behaviour (Chatzisarantis et al., 2007, p. 945). Conner et al. (2007) added moral norms, anticipated regret and past behaviour to the TPB model and also could confirm the predictive relevance of past behaviour.

A deeper insight in the decision making process provides the model from Kidwell and Jewell (2008) by highlighting the moderating impact of past behaviour on the self-efficacy-intention linkage. The study extends the existing models of behavioural intention. The findings confirm that on the one hand past behaviour does influence consumer decisions and on the other hand "...can influence the extent of deliberative processing when making a decision". In other words, past behaviour obviously moderates the influence "...of attitude and internal and external control on intention" (Kidwell / Jewell, 2008, p. 1162).

A remarkable contribution to the research on the intention-behaviour gap offers the already mentioned study by Pomery et al. (2009). TPB is based on the assumption, that a decision is the result of a deliberative, goaloriented process. In other words, behavioural options are considered, consequences of the option are evaluated and the decision to do something is made. It is an effective model of rational and / or reasoned behaviour in which behavioural intention is the main antecedent to behaviour. However, other studies have doubts about the relevance of intentions. Gibbons et al. (2003) developed the PWM (Prototype-Willingness-Model), which is based on three assumptions about risky behaviours among adolescents and young adults. One of the assumptions - risky behaviour is neither reasoned nor intentional - leads to the question of additional TPB constructs. Pomery et al. (2009) suggested inserting further predictors such as behavioural expectations and behavioural willingness. Also, the inclusion of moderators is proposed, e.g. experience and age (Pomery et al., 2009, pp. 894-896). Further relevant findings with respect to the paper at hand are (Pomery et al., 2009, pp. 904-905):

- $\quad$ Adolescents' behaviour is often unplanned

- $\quad$ Experience often plays a primary role in terms of the shift from reactive to reasoned responding

- $\quad$ Past behaviour is strongly related to future behaviour

The study gives an insight into the impact of experience on behavioural willingness, expectations and intentions in context of young people. There is evidence that "...the shift from reactive to reasoned processing that occurs with experience provides additional evidence for the dual-processing contention of the PWM [prototype/willingness model], specifically, the coexistence of a reasoned and a social reaction mode of procession" (Pomery et al., 2009, p. 906).

A recently published study from Wong and Mullan (2009) tries to improve predictive power of TPB for the context of breakfast consumption by additional variables like biologically imbued self-regulation, executive function and past behaviour. The results showed that by inclusion of past behaviour an increase in the predictive 
power of TPB and a diminished effect of intention on future behaviour is obtained. Past behaviour was the strongest predictor of future behaviour. With respect to the TPB model the authors concluded: “...Although the results indicated the strongest model of behaviour included past behaviour, it appears that past behaviour may be better viewed as a control variable ..." (Wong / Mullan, 2009, p. 499).

\section{"Past Behaviour Does Not Have Predictive Power" - Research Line}

Ajzen, the founder of TPB, is at the top of the group of researchers who oppose the relevance of Past Behaviour. He stated (Ajzen, 1991) that a correlation between past and future behaviour is only an indication of the behaviour's stability or reliability. Residual effects may reflect the influence of habit or other factors that are missing (Ajzen, 1991, p. 203). Ajzen (2002) examined in an additional analysis the residual effects of past on future behaviour in more details. He concluded that "...the residual impact of past behaviour is attenuated when measures of intention and behaviour are compatible and vanishes when intentions are strong and well performed, expectations are realistic, and specific plans for intention implementation have been developed" (Ajzen, 2002, p. 107). In detail Ajzen (2002) did argue against several empirical findings related to past behaviour as follows.

- $\quad$ Delibrate vs Spontaneous Modes of Operations (see Ouellette / Wood, 1998): Also behaviours that have become automatic are at the end controlled by cognitive factors like beliefs, attitudes and intentions. This is in contrast to the view that routinized behaviour is controlled by stimulus cues (Ajzen, 2002, p.109).

- $\quad$ Frequency of Past Behaviour as indicator of habit strength (see Triandis, 1977; 1980): A behaviour which has been performed many times does not provide evidence for habituation. Furthermore, habit strength and frequency of past behaviour are not necessarily proportional (Ajzen, 2002, pp. 108-109)

- Habits and the correlation between past and future behaviour (see Aarts et al., 1998; Ouellette / Wood, 1998): As long as the factors intention and perceptions of behavioural control remain unchanged (stable), the behaviour remain more or less the same (Ajzen, 2002, p. 110).

- Habits as Explanation for the Residual Impact of Past Behaviour on Future Behaviour (see Aarts et al., 1998; Ouellette / Wood, 1998): The residual effect of past on future behaviour is not necessarily based on habits. It could also reflect the operation of other factors. (Ajzen, 2002, pp. 110-111).

He continued to refuse the idea of Past behaviour being a relevant predictor in later publications (Ajzen, 2005). Past behaviour could not influence intention and future behaviour because it itself is object of influence by the other factors. The relationship rather is a reflection of the temporal stability (Ajzen, 2005, pp. 89 et seq.).

Further, Bamberg et al. (2003) argue, that the "...residual effect of prior on later behaviour also does not constitute direct evidence for the role of habitual processes. Several alternative explanations can be offered ..." (Bamberg et al., 2003, pp. 181 et seq.). In other words: while these researchers admit that habit could be a missing determinant, they underline alternative explanations, in particular the addition of further predictors like personal norms, anticipated regret or self-identity to the TPB (Bamberg et al., 2003, pp. 182-183).

A deeper insight into the field offers the following statement by Bamberg et al. (2003), who emphasize the reasoned character human behaviour generally seems to have: "In any event, past behaviour is clearly not always a good predictor of future behaviour. Only when circumstances remain relatively stable does prior behaviour make a significant contribution to the prediction of later action. Complex human behaviour is cognitively regulated and, even after numerous enactments, appears to be subject to at least some degree of monitoring. As a result, new information, if relevant and persuasive, can change behavioural, normative, and control beliefs, can affect intentions and perceptions of behavioural control, and influence later behaviour. We thus conclude that human social behaviour, although it may well contain automatic elements, is reasoned in nature.” (p. 188).

\subsection{Results}

Although some scholars vividly argue against the relevance of Past Behaviour, there are several studies available which could on the basis of empirical data show that indeed significant effects may exist. So far, several conceptualizations of Past Behaviour have been investigated: Past Behaviour, Frequency of Behaviour, Past Experience with Behaviour, and Habits. The last concept mentioned seems to be widely analyzed and indicates that 
human behaviour is likely to be automatic to a certain extent. The opponents of an inclusion of Past Behaviour argue that it is not this element which is relevant but an array of other factors which are associated to Past Behaviour. Furthermore, they claim that Past Behaviour is represented by the abundance - of not explicitly modelled background factors, which include ccording to Ajzen (2005) experience. On the other hand, even the opponents accept that under very specific circumstances Past Behaviour may play a relevant role. Furthermore, even they accept that human behaviour can be automatic to a certain extent. Last, not least, the question of how properly conceptualizing Past Behaviour seems to play a major role. Only integrating the construct and examining it for effects on intention and future behaviour seems not to account for TPB complexity. Rather, it has to be decomposed in several functions Past Behaviour may have.

\section{PROCESSING OF INFORMATION}

\subsection{Human Information Processing}

As mentioned in the introduction, this paper aims at developing an extended framework of TPB where past behaviour is included. Another important aspect, which may enhance our understanding of decision making and improve predictive strength of TPB is human information processing. Relevant starting points are briefly reviewed in this section and checked for a possible inclusion in the extended TPB model.

Information Processing is necessary for decision making. It is based on the idea of Neisser (1967) that “... intelligent organism operates in a perception-action cycle: the senses take in information from the environment, the $\mathrm{mid} / \mathrm{brain}$ performs computations on that information and the outputs of those computations are used to guide subsequent goal-directed actions" (Newell / Bröder 2008, p. 196). But such a biological organism information processing capacity is limited, therefore the organism needs to select. One option to incorporate this limitation into cognitive models is to propose heuristics or shortcuts. That enables the decision maker to make a "good enough judgement” (Newell / Bröder 2008, p. 198).

Simon (1982) doubts that humans are able to perfectly handle complex operations. Based on his bounded rationality approach, it can be argued that"...decision makers use simple strategies that reduce the amount of information and the number of cognitive operations ... identified a number of such strategies or heuristics that provide shortcuts to deliberation" ( Glöckner / Betsch 2008, p. 216). Furthermore, it could be stated that the amount to which the information processing depends on controlled or automatic processing is more or less a function of the involvement of memory (Newell / Bröder 2008, p. 196). Based on the dual-process models from Kahnemann and Frederick (2002), it could be distinguished between two systems: (1) One of them based on intuitive, automatic processing in which information is processed rapidly and in parallel and effortless to the decision maker; (2) The other one based on reflective, deliberate information processing, which involves deductive, effortful reasoning (Glöckner / Betsch 2008, pp. 215).

When it comes to information processing, there is no doubt that certain elements associated to Past Behaviour deserve to be mentioned. "When individuals encounter a decision situation, salient and associated information is activated in memory and a mental representation is formed that combines given and memory-stored information" (Newell / Bröder 2008, p. 198). Furthermore, “...tasks that have been encountered numerous times in the past become straightforward to execute or solve because relevant actions or solutions can be retrieved from memory and thus performance is less dependent on active attention" (Newell / Bröder 2008, p. 196). The linkage between Past Behaviour and Information Processing could also be found in literature ten years ago in the conjunction with context stability (see Quellette / Wood, 1998). In domains which do not facilitate habits, Past Behaviour was a weak predictor for future behaviour. Hence, with respect to information processing, stable contexts and habits, respectively reduce the need of the processing. A good relation between Past and Future Behaviour could be expected. This view is supported by the cognitive-motivational model of habit. Aarts and Dijksterhuis (2000) made the case that “... when habits were established, simply activating a goal related to drinking automatically evoked the habitual responses" (Sheeran et al., 2005a, p. 60). It could be described as automaticity in goal directed behaviour. 
Glöckner and Betsch (2008) concluded that for an understanding of human decisions, both automatic and deliberate processes should be considered.

\subsection{Relevant concepts of information processing}

In line with Glöckner and Betsch (2008) and Newell and Bröder (2008), also Kidwell and Jewell (2008) highlight heuristics in regard to decision making processes. Decision making according to these researchers is based on two types of mental processes: those with high level and those with low level of cognitive effort. They distinguished between deliberative and heuristic processing of information. Linking this idea to TPB, on the one hand subjective norm and attitude as TPB-Constructs are "...often considered to be a cognitive antecedent of one's behavioural intention" and therefore could be seen as a deliberative driven processing of information. Past Behaviour moderates the relationship between attitude / subjective norm and intention in the way that low levels of Past Behaviour will strengthen the relation (Kidwell / Jewell, 2008, pp. 1152-1154). Similar to this study, the approach of Sheeran et al. (1999), referring to stable intentions, deserves to be mentioned. Their findings suggest that stable intentions were better predicted by attitudes and less by perceived behaviour control. In other words, intentions more strongly based on attitudes ("more desirability based") offer better prediction of behaviour than intentions which are predominantly based on perceived behaviour control ("more feasibility based"). On the other hand, they assume that heuristic information processing may also be important, especially in case of internal and external control. The role of Past Behaviour could be, like for the other construct, a moderating one. The concluded that Past Behaviour moderates the relation between perceived internal and external control and intention in the way, that in contrast to the other TPB-Constructs, a high level of Past Behaviour strengthens the relation (Kidwell / Jewell, 2008, pp. 1154-1155).

A specific form of different processing modes or styles, respectively, can be subsumed under the concept of cognitive style. The intuitive cognitive style of information processing is characterized by the ability to take information and form them to an interesting idea, whereas the analytic style is more characterized by refining and improving the idea (Kickul et al., 2009, p. 442). The findings of Kickul and her colleagues (2009) demonstrate that in an entrepreneurial context individuals who prefer a more analytic style showed a greater self-efficacy for planning and implementation stages in comparison to individuals with a more intuitive style. The existence of different cognitive styles of information processing lead to the assumption that the information processing is less deliberative as sometimes supposed. As an example, intuitive style individuals partly overlook necessary stages of the venture creation process which do not perfectly fit to their preferred style (Kickul et al. 2009, p. 448).

The next linkage between TPB and Information Processing is based on the decision making process regarding risk behaviour. Pomery et al. (2009), distinguishing planned and reactive behaviour, stated that people with less experience with risk behaviour and risk-conductive situations such as smoking will demonstrate a rather reactive than planned behaviour. Such a not fully planned or intended behaviour is often a reaction the social environment (Pomery et al., 2009, p. 904). A rise in experience implies “.... an increased awareness of what is likely to happen in the future (BE [Behavioural Expectation]), as well as increased contemplation of the behaviour and its consequences..." (Pomery et al., 2009, p. 896). This is another interesting hint on different kinds of information processing which could happen under specific circumstances.

Implementation Intention and Processing of Information also is linked. Orbell et al. (1997) presented findings which verify that planning a behaviour could generate memory traces. Regarding the memory the author stated: “...memory for an intention to perform BSE [breast self-examination] every Sunday is capable of environmental elicitation, whereas memory for an intention to perform every fourth Sunday may require conscious selfinstructions" (Orbell et al., 1997, p. 948). This statement shows that maybe different levels of Information Processing exist. Furthermore, it can be supposed that implementation intentions reduce the risk of forgetting to perform the behaviour. Gollwitzer (1993) reports that the formation of implementation intention is helpful to recall the chosen option. To sum up "...the process by which past behaviour controls future behaviour and the process by which implementation intentions direct future behaviour might be the same. In both cases there is an association in memory between the behaviour and certain environmental cues" (Sheeran / Orbell, 1999, pp. 352-353). It could be seen, that the link between implementation intention and information processing has to do with the existence of memory traces. 


\subsection{Results}

From this brief discussion, several aspects relevant to TPB need to be highlighted. Generally, information processing seems to be relevant when talking about developing the intention to perform a specific behaviour and plans to implement it. Basically, human decision making should involve becoming aware of the problem, gathering and analyzing information and making the decision. Unfortunately, human rationality is limited; the same is true for human information processing capacity. Therefore, such a perfect decision making procedure is rather unrealistic if not impossible. While the perfect procedure thus is likely to be absent in everyday life, there exist certain forms of information processing mode which can be observed very often. On the one hand, there is a rather intuitive form which also could be assigned heuristic elements; on the other hand, deliberative, analytic information processing is present in everyday life. Furthermore, these forms can be linked to two common cognitive styles, i.e. intuitive as well as analytic style. Based on TRA, TPB and in particular the development of goal intentions is basically reasoned (Bamberg et al., 2003), i.e. rather non-intuitive and non-automatic. Nevertheless, certain aspects such as context and an individual's cognitive style influence the generation of goal intentions. With respect to implementation intentions, it can be stated that the more often such intentions are developed or planned, respectively, the less necessary conscious self-instructions are (Orbell et al., 1997). In other words: the more decision-makers practice such planning activities, the less reasoned or analytic this development process is likely to be.

\section{CONCEPTUAL FRAMEWORK}

In this section, the conceptual framework for an extended TPB model will be developed which is based on the considerations presented above.

\section{Basic framework}

As already mentioned, the extended model is based on TPB. Beyond doubt, the main elements of TPB need to be integrated into this framework. Thus, intentions are basically formed based on attitudes towards behaviour, perceptions of social norms as well as perceived control over behaviour. The intention part consists of two components: on the one hand, following Ajzen (1991), there exist goal intentions, i.e. the general motivation to behave in a certain way. On the other hand, based on the works by Gollwitzer $(1996 ; 1999)$ and his colleagues (e.g. Gollwitzer / Barndstaetter, 1997) implementation intentions are part of the model, standing for the cognitive processes dealing with planning to carry out the behaviour. It is straightforward to assume that both intention types are sequentially developed, with goal intention being the first one. As soon as the motivation to perform behaviour exists, plans to implement it can be developed. Please note that Gollwitzer and Schaal (1998) argue that these intentions are formed at least to a certain extent automatically when a specific context is encountered.

\section{Information processing}

Basically, TPB implies reasoning and careful thinking. Therefore, coming to a decision very likely involves a certain amount of information processing. As TPB is founded on the idea that intentions are based on reasoning, a systematic, deliberative and analytic procedure can be assumed to take place. But as already shown the amount of reasoning depends on several factors, in particular context and type of behaviour. Stable contexts reduce the necessity to reason (and to systematically and analytically process information) (cf. Oulette/Wood, 1998). Here, the development of certain automatisms in terms of cognitive processes can be assumed. Thus, there seems to exist - at least on the level of intention development - both deliberative and automatic processing styles. And, this is even more important, they do exist both at any given time. The author follows the suggestion by Bamberg et al. (2003) that each behaviour is at least to a certain extent reasoned. The question which processing mode is - maybe completely - dominating the other depends on several aspects which have been already mentioned. Furthermore, decision situations require an individual to gather and analyze information. In complex situations, it is very likely that individuals account for their limited information processing capacity by using short-cuts and heuristics which may cause cognitive biases (e.g. Das/Teng, 1999). Again, as this information processing seems to be relevant for the generation of goal intentions, there seem to exist automatisms in terms of heuristics on intention level. As this of course depends on context and type of behaviour, a general model should contain deliberative and automatic processing at the same time. Thus, two basic information processing forms are integrated: one deliberative and rather analytic, one more automatized, being related to heuristics and intuition. 


\section{Past behaviour}

It has been shown, that stable intentions are good predictors of behaviour (e.g. Sheeran et al., 1999). There is evidence that experiences foster the development of such intentions. On the other hand, in case intentions are not stable, Past Behaviour has been found to be a good predictor of future behaviour. As experience clearly is based on Past Behaviour, in each case the latter deserves to be integrated in one form or another. One approach surely is to integrate experience. Ajzen (2005) himself admits that it is an important background factor influencing the basic TPB elements. As this element seems to influence information processing modes, it should be modelled explicitly; as an example, individuals are less reactive and more thoughtful when they gain experience (Pomery et al., 2009). Another aspect dealing with past behaviour - being related to the intention level of the framework - deserves to be mentioned. If certain behaviours are repeated very often, this seems to support the development of habits. As already has been shown, the latter reduce the level of information processing. This again underlines the relevance of Past Behaviour and indicates another element to be integrated into the framework: automatism. Please note, that these automatisms refer to how information are gathered and beliefs are evaluated. In other words, the above mentioned inclusion of a rather automatic processing style also accounts for an important facet of Past Behaviour. Automatisms seem to refer in particular to implementation intentions: regular planning reduces the need of deliberative processing as planning generates memory traces (Orbell et al., 1997). Furthermore, it can be argued that certain stimuli - as for example having certain goal intentions - are associated with implementation schemes stored in memory. The richer the memory, the less necessary are conscious self-instructions (cf. Orbell et al., 1997).

Decision situations, especially when it comes to difficult strategic ones, always imply the withdrawing of information stored in memory and generating a mental representation of the problem in question. Thus, to come to conclusion in such complex - i.e. difficult and dynamic (Ringlstetter, 1997) - situations, deliberative processing is necessary. Of course, very often heuristics are used. But triggering them does not mean fully-automatized processes are started. Rather, these heuristics also imply deliberative processing of information. Complex situations may occur often and may furthermore show similarities although not being completely identical. Such situations always require an individual approach, rendering fully automized processing modes or even habits rather unrealistic. Nevertheless, implementation intentions come to the foreground when goal attainment becomes relevant. The formation of these intentions "involves involves a conscious act of willing that results in an association in memory between mental representations of the specified opportunities (situations)and the means of attaining goals (cognitive or behavioural responses)" (Sheeran et al., 2005b, p. 280). Thus, there very likely are similarities in implementation schemes in case specific situations that require an individual to act in a certain way are similar.

I feel that it is necessary to make a clear distinction to the work by Kidwell and Jewell (2007). They argued that TPB can be characterized by two different information processing modes, i.e. deliberative and heuristic processing. Interestingly, they link the former to attitudes and social norms and the latter to perceived behavioural control (Kidwell/Jewell, 2007, p. 1155), implying that heuristic processing is mainly non-deliberative. Reasoning about the control over the behaviour in question implies evaluating control beliefs which too seems to be deliberative. Furthermore, even heuristics seem to require deliberative processing. As an example, availability could be mentioned: when one imagines what could happen, she / he remembers similar past situations. In that case certain information are gathered and a mental representation is built. The problem is that only a certain facet of information is addressed, but basically deliberative processing is part of the heuristic. In other words: heuristics do not necessarily imply non-deliberative processing. A much better approach in terms of processing styles seems to categorize them into analytic and intuitive (cf. Kickul et al., 2009). Furthermore, attitudes seem to be somewhat stable over time, especially when generalized attitude strength is high (Prislin, 1996) so it is not clear why particularly the relationship between attitude and implementation should be deliberative in nature while PBC is heuristic. Furthermore, Ajzen (2001) summarizing a considerable amount of research with respect to attitudes argues that attitudes are generally activated automatically. This supports the idea that evaluative meaning of an object is to a certain - maybe to a large - extent created automatically. Of course, this does not support that attitude evaluation is predominantly deliberative in nature.

In sum, these considerations suggest that a distinction between deliberative, analytic and automatic, intuitive processing is likely to be the better choice (cf. Glöckner/Betsch, 2008). Furthermore, both modes seem to be related to all - and not only subsets - of the basic TPB elements. 
The framework described above is schematically presented in Figure 3.

\section{DISCUSSION AND CONCLUSION}

While TPB is an established theory to explain human behaviour, the role of Past Behaviour has been vividly discussed since Ajzen's (1991) seminal paper on the theory. Despite the fact that there is one line of research which clearly neglects the relevance of Past Behaviour's predictive power it has been included in the extended TPBframework presented in this paper. However, the author followed some ideas the "against Past Behaviour" school has developed. The main aspect here is decomposition - Past Behaviour is not included as an independent construct nor is it directly linked to future behaviour. Rather, it is acknowledged that Past Behaviour has several functions which influence TPB's basic process: reasoning. On the one hand, experiences are explicitly integrated; on the other, automatisms as another seemingly relevant aspect are included.

Furthermore, Past Behaviour is integrated in the framework by linking it to human information processing. Such modes have been mentioned in literature so far only a few times. An application found in literature is the dualmodes of deliberative and heuristics-oriented processing. Despite the fact that there is evidence that this approach may add to a better explanation of goal intention building, it seems to have some weaknesses. Therefore, an alternative idea has been seized: while the basic process in TPB is reasoning - which implies analytical, deliberative processing of information - it very likely also includes certain automatisms. Both modes are likely to be present in each individual, maybe at the same time. There is no doubt that the dominating mode varies across contexts and type of behaviours. It is further argued that the evaluation process which leads to goal intention as well as the developing of concrete plans to perform the behaviour - resulting in implementation intentions - are partially based on (semi-) automatisms.

A lot of researchers mentioned the relevance of habits. There are many hints which suggest that this concept indeed really matters. Although the framework presented here includes (semi-)automatisms in developing intentions, habits are not integrated as separate construct. This is mainly because the author feels that the proposition by Bamberg et al. (2003) - i.e. each human behaviour implies to some extent reasoning - is more realistic than the assumption of completely automized behaviours. Furthermore, such perfect habits would be realistic probably for very simple behaviours only, maybe for beer-drinking. If such thing as a perfect habit is a rather rare phenomenon and the existence of not-so-perfect habits is more realistic, the latter should be modelled. That's exactly the approach the author followed when developing the framework presented above.

This paper has presented an extended model of TPB which aims at properly integrating past behaviour as well as information processing modes. It proofed to be useful, to link past behaviour to these modes in order to conceptualize it. Basically, this paper's theoretical contribution is twofold. First, it has been shown why and how past behaviour can be properly integrated in TPB. It was managed to do this even by taking into account the retentions the "Against Past Behaviour" research line presents. Second, information processing has been linked to TPB, overcoming deficiencies of the few earlier works in this field. It appears that the idea of deliberative, analytic processing as well (semi-)automatism much better fits how humans develop goal and implementation intentions, respectively (cf. Bamberg et al., 2003; Sheeran et al., 2005a).

Beyond doubt, considerable research work lies ahead. First of all, Past Behaviour has been decomposed and two main elements have been integrated. It has to be examined, whether further functions may be relevant. Furthermore, other factors than Past Behaviour are likely to exist the inclusion of which could improve explained variance of intention. Second, the linkages proposed in this paper require empirical testing over a set of different behaviour and contexts. Of particular relevance are internationalisation decision situations, which should be analyzed over time, i.e. it has to be examined how the development of corresponding intentions varies over time for a set of decision makers. This would allow revealing the paths of the exact effects of experiences and (semi-) automatisms. 


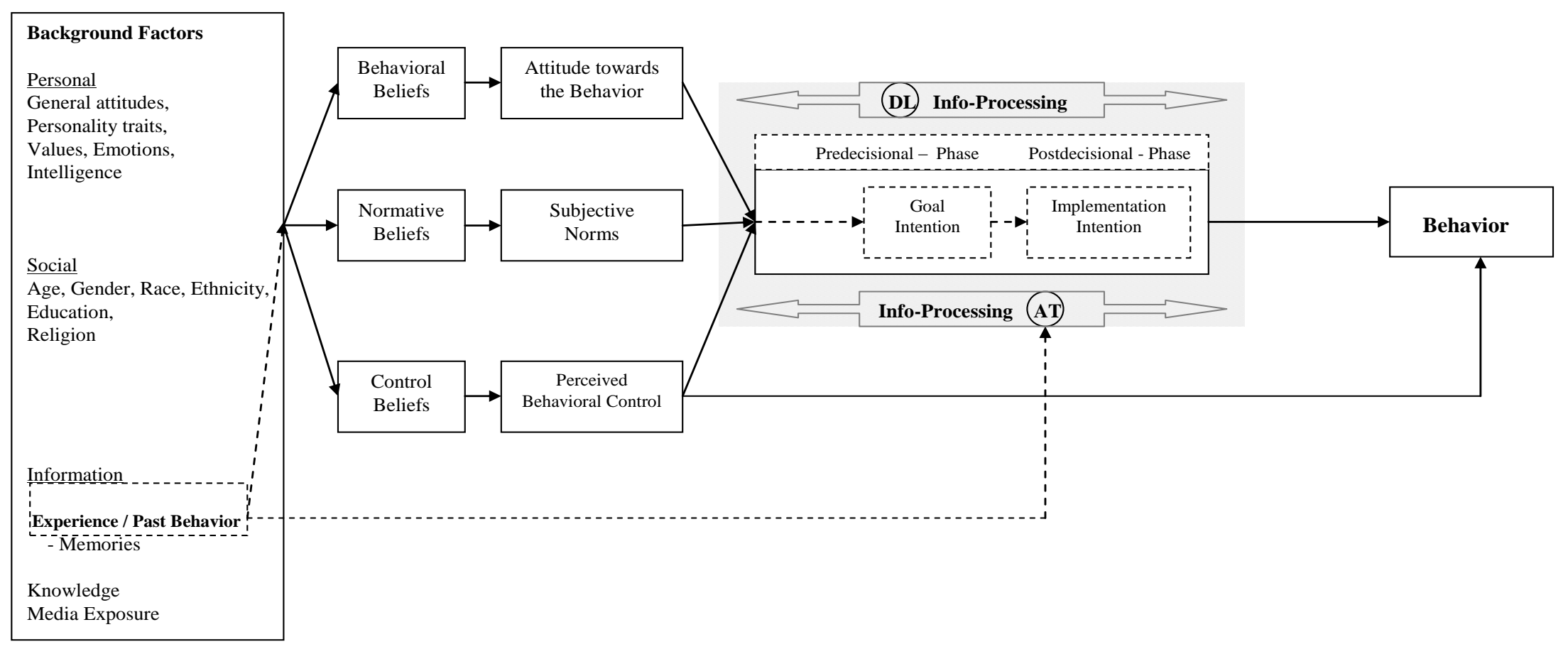

Figure 3: Combined Model - based on TPB according to Ajzen (2005) and MAP according to Heckhausen / Gollwitzer (1991 / 1996)

Legend: $\quad$ DL $=$ Deliberative Guided Processing of Information $; \mathbf{A T}=$ Automatic Guided Processing of Information

Solid Line $\quad=$ Elements based on TPB

Dashed Line $\quad=$ Elements based on MAP

Structured Area $=$ Elements based on Information Processing 


\section{AUTHOR INFORMATION}

Lutz Sommer is Professor at Albstadt-Sigmaringen University in the Department of Business Administration and Engineering. He studied in Germany (Berlin Institute of Technology / University of Hagen) and Poland (University of Gdansk) and holds a BEng / MEng in Engineering, a MSc in Business Administration and Engineering, a BSc / MSc in Business Administration and Economics as well as a PhD in Economics.

His research activities deal with the internationalization activities of Small and Medium-Sized Enterprises (SME). In particular, the focus is on the influence of socio-psychological factors on the owner-managers' decision making processes in terms of internationalization.

\section{BIBLIOGRAPHY}

1. Aarts, H. (1996): Habit and decision making: The case of travel mode choice, Doctoral Dissertation, University of Nijmegen, Netherland

2. Aarts, H. (2007): Health and goal-directed behaviour: The nonconscious regulation and motivation of goals and their pursuit; in: Health Psychology Review; Vol. 1, Nr. 1, pp. 53-82

3. Aarts, H. / Dijksterhuis, Ap (2000): Habits as Knowledge Structures: Automaticity in Goal-Directed Behaviour; in: Journal of Personality and Social Psychology, Vol. 78, No. 1, pp. 53-63

4. $\quad$ Aarts, H. / Verplanken, B. / Knippenberg, A. (1998): Predicting Behaviour From Action in the Past: Repeated Decision Making or a Matter of Habit? ; in: Journal of Applied Social Psychology, Vol. 28, No. 15, pp. 1355-1374

5. Achtziger, A. / Gollwitzer, P. (2007): Rubicon Model of Action Phases; in: Encyclopedia of social psychology, pp. 769-770

6. Aharoni, Y. (1999): The Foreign Investment Decision Process; in: Buckley, P.J./Ghaui, P.N. (eds.): The Internationalisation of the Firm - A Reader, 2nd ed., London, pp. 3-13

7. Ajzen, I. (1991): The theory of planned behaviour: Organizational Behaviour and Human Decision Processes, Vol. 50, pp. 179-211

8. Ajzen, I. (2001): Nature and Operation of Attitudes; in: Annual Review of Psychology, Vol. 52, pp. 27-58

9. Ajzen, I. (2002): Residual Effect of Past on Later Behaviour: Habituation and Reasoned Action Perspectives; in: Personality and Social Psychology Review, Vol. 6, No. 2, pp. 107-122

10. Ajzen, I. (2005): Attitudes, Personality and Behaviour; Open University Press - Second Edition, McGrawHill Education, ISBN 0335217036

11. Albarracin, D. / Johnson, B. / Fishbein, M. / Muellerleile, P. (2001): Theories of Reasoned and Planned Behaviour as Models of Condom Use - A Meta Analysis; in: Psychological Bulletin, Vol. 127, No. 1, pp. $142-161$

12. Armitage, C. / Conner, M. (2001): Efficacy of the Theory of Planned Behaviour: A meta-analytic review; in: British Journal of Social Psychology, Vol. 40, pp. 471-499

13. Athanassiou, N./Nigh, D. (2002): The Impact of the Top Management Team's International Business Experience on the Firm's Internationalisation: Social Networks at Work; in: Management International Review, Vol. 42, No. 2, pp. 157-181

14. Bamberg, S. (1996): Integration des Konstrukts Habit in die Theorie des geplanten Verhaltens; in: Zeitschrift für Sozialpsychologie, Vol. 27, pp. 295-310

15. Bamberg, S. / Ajzen, I. / Schmidt, P. (2003): Choice of travel mode in the theory of planned behaviour: The roles of past behaviour, habit, and reasoned action; in: Basic and Applied Social Psychology, Vo. 25, pp. $175-188$.

16. Bargh, J.A. (1989): Conditional Automaticity: Varieties of Automatic Influence in Social Perception and Cognition; in: Uleman, J.S./Bargh, J.A. (eds.): Unintended Thought, New York, pp. 3-51

17. Bargh, J.A./Gollwitzer, P.M. (1994): Environmental control of goal-directed action: Automatic and strategic contingencies between situations and behaviour; in: Spaulding, W.D. (ed.): Integrative Views of Motivation, Cognition, and Emotion, Nebraska Symposium on Motivation, Vol. 41, pp. 71-124

18. Baron, R.M./Kenny, D.A. (1986): The Moderator-mediator Variable Distinction in Social Psychological Research: Conceptual, Strategic, and Statistical Considerations; in: Journal of Personality and Social Psychology, Vol. 51, No. 6, pp. 1173-1182 
19. Brigham, K.H./DeCastro, J.O./Shepherd, D.A. (2007): A Person-organization Fit Model of Ownermanagers' Cognitive Style and Organizational Demands; in: Entrepreneurship Theory \& Practice, Vol. 31, No. 1, pp. 29-51

20. Chatzusarantis, N. / Hagger, M. / Smith, B. (2007): Influences of perceived autonomy support on physical activity within the theory of planned behaviour; in: European Journal of Social Psychology, Vol. 37, pp. 934-954

21. Conner, M. / Warren, R. / Close, S. (1999): Alcohol Consumption and the Theory of Planned Behaviour: An Examination of the Cognitive Mediation of Past Behaviour; in: Journal of Applied Social Psychology, Vol. 29, No. 8, pp. 1676-1704

22. Conner, M. / Lawton, R. / Parker, D. / Choriton, K. / Manstead, A. / Stradling, S. (2007): Application of the theory of planned behaviour to prediction of objectively assessed breaking of posted speed limits; in: British Journal of Psychology, Vol. 98, No. 3, pp. 429-453

23. Cooke, R./Sheeran, P. (2004): Moderation of Cognition-Intention and Cognition-Behaviour Relations: A Meta-analysis of Properties of Variables from the Theory of Planned Behaviour; in: British Journal of Social Psychology, Vol. 43, No. 2, pp. 159-186

24. Czinkota, M.R./Johnston, W.J. (1983): Exporting: Does Sales Volume Make a Difference?; in: Journal of International Business Studies, 14 (1983), pp. 147-153

25. Das, T.K./Teng, B.-S. (1999): Cognitive Biases and Strategic Decision Processes: An Integrative Perspective; in: Journal of Management Studies, Vol. 36, No. 6, pp. 757-778

26. Fen, Y. / Sabaruddin, N.(2008): An Extended Model of Theory of Planned Behaviour in Predicting Exercise Intention, in: International Business Research, Vol. 1, No. 4, pp. 108- 122

27. Fishbein, M. / Ajzen, I. (1975): Belief, attitude, intention and behaviour: An instruction to theory and research; Addison-Wesley

28. Freeman, S./Cavusgil, S.T. (2007): Toward a Typology of Commitment States Among Managers of BornGlobal Firms: A Study of Accelerated Internationalisation; in: Journal of International Marketing, 15, No. 4 (2007), pp. 1 - 40

29. George, J. (2002): Influences on the intent to make internet purchases; in: Internet Research-Electronic Networking Applications and Policy, Vol. 12, No. 2, pp. 165-180

30. Gibbons, F. / Gerrad, M. / Lane, D. J. (2003): A social-reaction model of adolescent health risk; in: Social psychological foundations of health and illness, pp. 107-136

31. Glöckner, A./Betsch, T. (2008): Modeling Option and Strategy Choices with Connectionist Networks: Towards an Integrative Model of Automatic and Deliberate Decision; in: Judgment and Decision Making, Vol. 3, No. 3, pp. 215-228

32. Gollwitzer, P.M. (1993): Goal Achievement: The Role of Intentions; in: European Review of Social Psychology, Vol. 4, pp. $141-185$

33. Gollwitzer, P.M. (1996): The rubicon model of action phases; in: J. Kuhl, \& H. Heckhausen (Ed) Motivation, volition, and action; Encyclopedia of psychology; Vol. 4, pp. 531 - 582

34. Gollwitzer, P.M. (1999): Implementation Intentions: Strong Effects of Simple Plans; in: American Psychologist, Vol. 54, No. 7, pp. 493-503

35. Gollwitzer, P. M. /Brandstätter, V. (1997): Implementation Intentions and Effective Goal Pursuit; in: Journal of Personality and Social Psychology, Vol. 73, No. 1, pp. 186-199

36. Gollwitzer, P. M./Schaal, B. (1998): Metacognition in Action: The importance of Implementation Intentions; in: Personality and Social Psychology Review, Vol. 2, No. 2, pp. 124-136

37. Gomez-Gras, J.-M./Galiana Lapera, D.-R./Mira-Solves, I./Verdu-Jover, A.-J./Sancho-Azuar, J. (2009): Exploring Firms' Early Internationalisation from a Cognitive Perspective: A Conceptual Model; in: International Journal of Globalisation and Small Business, Vol. 3, No. 2, pp. 186-200

38. Hagger, M. / Chatzisaranits, N. / Biddle, S. (2002): A meta-analytic review of the theories of reasoned action and planned behaviour: Predictive validity and the contribution of additional variables; in: Journal of Sport and Exercise Psychology, Vol. 24, pp. 3-32

39. Halikias, J./L. Panayotopoulou (2003): Chief Executive Personality and Export Involvement; in: Management Decision, 41, No. 4 (2003), pp. 340-349

40. Hambrick, D.C./Mason, P.A. (1984): Upper Echelons: the Organization as a Reflection of its Top Managers; in: Academy of Management Review, 9, No. 2 (1984), pp. 193 - 206

41. Heckhausen, H. (1991): Abwägen und planen; Hogrefe; Göttingen 
42. Heckhausen, J. (1999): Development regulation in adulthood-age-normative and sociostructural constraints as adaptive challenges; in: Cambridge University Press

43. Hodgkinson, G.P./Maule, A.J. (2002): The Individual in the Strategy Process: Insights from Behavioral Decision Research and Cognitive Mapping; in: Huff, A.S./Jenkins, M. (eds.): Mapping Strategic Knowledge, London

44. Hodgkinson, G. P./Sparrow, P. R. (2002): The Competent Organization: A Psychological Analysis of the Strategic Management Process, Milton Keynes

45. Hooft, E.J.A./Born, M.P./Tarish, T.W./Van der Flier, H./Blonk, R.W.B. (2005): Bridging the Gap Between Intentions and Behaviour: Implementation Intentions, Action Control, and Procrastination; in: Journal of Vocational Behaviour, Vol. 66, No. 2, pp. 238-256

46. Kahneman, D./Frederick, S. (2002): Representativeness Revisited: Attribute Substitution in Intuitive Judgment; in: Gilovich, T./Griffin, D./Kahneman, D. (eds): Heuristics and Biases: The Psychology of Intuitive Judgment, New York, pp. 49-81

47. Keh, H.T./Foo, M.D./Lim, B.C. (2002): Opportunity Evaluation under Risky Conditions: The Cognitive Processes of Entrepreneurs; in: Entrepreneurship Theory \& Practice, 27, No. 2 (2002), pp. 125-148

48. Kickul, J. / Gundry, L. / Barbosa, S. / Whitcanack, L. (2009): Intuition Versus Analysis? Testing Differential Models of Cognitive Style on Entrepreneurial Self-Efficacy and the New Venture Creation Process; in: Entrepreneurship Theory and Practice, pp. 439-453

49. Kidwell, B. / Jewell, R. (2008): The Influence of Past Behaviour on Behavioral Intent - An InformationProcessing Explanation; in: Psychology \& Marketing, Vol. 25, No. 12, pp. 1151-1166

50. Knight, G.A. (2001): Entrepreneurship and Strategy in the International SME; in: Journal of International Management, Vol. 7, No. 3, pp. 155-171

51. Knussen, C. / Yule, F. / MacKenzie, J. / Wells, M. (2004): An analysis of intentions to recycle household waste: The roles of past behaviour, perceived habit, and perceived lack of facilities; in: Journal of Environmental Psychology, Vol. 24, pp. 237-246

52. Krueger, N. / Carsrud, A. (1993): Entreoreneurial intentions. Applying the theory of planned behaviour, in: Entrepreneurship \& Regional Development, Vol. 5, pp. 315-330

53. Krueger, N.F./Reilly, M.D./Carsrud, A.L. (2000): Competing Models of Entrepreneurial Intentions; in: Journal of Business Venturing 15, No. 5-6 (2000), pp. 411-432

54. Kuhl, J. (1985): Volitional mediators of cognitive-behaviour consistency: Self regulatory processes and action control; in: J. Kuhl \& J. Beckmann: Action Control: Form Cognition to Behaviour, pp. 101-128

55. Leonidou, L.C./Katsikeas, C.S./Piercy, N.F. (1998): Identifying Managerial Influences on Exporting: Past Research and Future Directions; in: Journal of International Marketing, Vol. 6, No. 2, pp. 74-102

56. Limayem, M. / Hirt, S. / Cheuung, C. (2003): Habits in the Cintext of IS Continuance: Theory Extension and Scale Development; Proceedings of the Eleventh European Conference of Information Systems - ECIS

57. Logan, G. D. (1989): Automaticity and Cognitive control; in: Uleman, J.S./Bargh, J.A. (eds.): Unintended Thought, New York, pp. 52-74

58. McBroom, W.H./Reid, F.W. (1992): Towards a Reconceptualization of Attitude-Behaviour Consistency; in: Social Psychology Quarterly, Vol. 55, No. 2, pp. 205-216

59. McDougall, P.P./Oviatt, B.M. (1997): International Entrepreneurship Literature in the 1990s and directions for future research; in: Sexton, D.L./Simlor, R.W. (Eds.): Entrepreneurship 2000, Chicago, pp. 291-320

60. McDougall, P.P./Oviatt, B.M. (2000): International Entrepreneurship: the Intersection of two Research Paths; in: Academy of Management Journal, 43, No. 5 (2000), pp. 902-906

61. Mair, J./Thurner, C. (2005): Middle Managers in a Medium-sized Firm: Their Involvement in the Internationalisation Strategy Process, Working Paper No. 615, IESE Business School, University of Navarra

62. Miesenböck, K.J. (1988): Small business and Exporting: A literature Review; in: International Small Business Journal, 6, No. 2 (1988), pp. 42 - 61

63. Mitchell, R. K./Smith, J. B./Morse, E. A./Seawright, K. W./Peredo, A. M./McKenzie, B. (2002): Are Entrepreneurial Cognitions Universal? Assessing Entrepreneurial Cognitions Across Cultures; in: Entrepreneurship Theory and Practice, 27, No. 2 (2002), pp. 9-29

64. Mitchell, R.K./Busenitz, L.W./Bird, B./Gaglio, C.M./McMullen, J.S./Morse, E.A./Smith, J.B. (2007): The Central Question in Entrepreneurial Cognition Research 2007; in:

65. Neisser, U. (1967): Cognitive Psychology. Englewood Cliffs 
66. Newell, B. / Bröder, A. (2008): Cognitive processes, models and metaphors in decision research; in: Judgment and Decision Making; Vol. 3, No. 3, pp. 195-204

67. Orbell, S. / Hodgkins, S. / Sherran, P. (1997): Implementation Intention and the Theory of Planned Behaviour; in: Personality and Social Psychology Bulletin, Vol. 23, pp. 945-954

68. Ouellette, J. / Wood, W. (1998): Habit and intention in everyday life: the multiple processes by which past behaviour predicts future behaviour; in: Psychological Bulletin, Vol. 124, pp. 54-74

69. Oviatt, B.M./McDougall, P.P. (2005): Defining International Entrepreneurship and Modeling the Speed of Internationalisation; in: Entrepreneurship Theory \& Practice, Vol. 29, No. 5, pp. 537-553

70. Pomery, E. / Gibbons, F. / Reis-Bergman, M. / Gerrard, M. (2009): From Willingness to Intention: Experience Moderates the Shift From Reactive to Reasoned Behaviour; in: Personality and Social Psychology Bulletin, Vol 35, No. 7, pp. 894-908

71. Prislin, R. (1996): Attitude Stability and Attitude Strength: One is Enough to Make It Stable; in: European Journal of Social Psychology, Vol. 26, No. 3, pp. 447-477

72. Reid, S.D. (1981): The Decision-maker and Export Entry and Expansion; in: Journal of International Business Studies, Vol. 12, No. 2, pp. 101-112

73. Rhodes, R. / Courneya, K. (2003): Modeling the theory of planned behaviour and past behaviour; in: Psychology, Health \& Medicine, Vol. 8, No. 1, pp. 57-69

74. Ringlstetter, M. (1997): Organisation von Unternehmen und Unternehmensverbindungen, München

75. Ruzzier, M./Hisrich, R.D./Antoncic, B. (2006): SME Internationalisation Research: Past, Present, and Future; in: Journal of Small Business and Enterprise Development, 13, No. 4 (2006), pp. 476-497

76. Sadler-Smith, E/Badger, E. (1998): Cognitive Style, Learning, and Innovation; in: Technology Analysis and Strategic Management, Vol. 10, No. 2, pp. 247-265

77. Schank, R.C./Abelson, R.P. (1995): Knowledge and Memory: The Real Story; in: Wyer, R.S. (ed): Knowledge and Memory: The Real Story. Hillsdale, pp. 1-85

78. Shane, S./Venkataraman, S. (2000): The Promise of Entrepreneurship as a Field of Research; in: Academy of Management Review, 25, No. 1 (2000), pp. 217-226

79. Sheeran, P. (2002): Intention-behaviour relations: A conceptual and empirical review; in: European Review of Social Psychology, Vol. 12, pp. 1-36

80. Sheeran, P. / Aarts, H. / Custers, R. / Rivis, A. / Webb, T. / Cooke, R. (2005): The goal-dependent automaticity of drinking habits; in: British Journal of Social Psychology, Vol.44, pp. 47-63

81. Sheeran, P./Milne, S./Webb, T.L./Gollwitzer, P.M. (2005): Implementation Intentions and Health Behaviour; in: Conner, M. (ed.): Predicting Health Behaviour, New York, pp. 276-323

82. Sheeran, P. / Orbell, S. (1999): Implementation Intentions and Repeated Behaviour: Augmenting the Predictive Validity of the Theory of Planned Behaviour; in: European Journal of Social Psychology, Vol. 29, No. 2-3, pp. 349-369

83. Sheeran, P. / Orbell, S. (1998): Do intentions predict condom use? Meta-analysis and examination of six moderator variables; in: British Journal of Social Psychology, Vol. 37, pp. 231-250

84. Sheeran, P. / Orbell, S. / Trafimow, D. (1999): Does the Temporal Stability of Behavioral Intentions Moderate Intention-Behaviour and Past Behaviour-Future Behaviour Relations? ; in: Personality and Social Psychology Bulletin, Vol. 25, , No. 6, pp. 724-730

85. Simon, H.A. (1957): Models of Man Social and Rational: Mathematical Essays on Rational Human in a Social Setting, New York

86. Smith J. R. / Manstead, A. / Terry, D./Louis, W. (2007): Interaction Effects in the Theory of Planned Behaviour: The interplay of Self-Identity and Past Behaviour; in: Journal of Applied Social Psychology, Vol. 37, No. 11, pp. 2726-2750

87. Sniehotta, F. / Scholz, U. / Schwarzer, R. (2005): Bridging the intention-behaviour gap - Planning, selfefficacy, and action control in the adoption and maintenance of physical exercise; in: Psychology and Health, Vol. 20, No. 2, pp. $143-160$

88. Traindis, H. (1980): Values, attitudes, and interpersonal behaviour; in: H. Howe\&M. Page, Nebraska Symposium on Motivation, Vol. 27, pp. 195-259

89. Triandis, H. (1977): Interpersonal Behaviour; Monterey CA; Brooks/Cole

90. Ward, T.B. (2004): Cognition, Creativity, and Entrepreneurship; in: Journal of Business Venturing, 19, No. 2 (2004), pp. 173-188 
91. Warshaw, P.R./Davis, F.D. (1985): Disentangling behavioral intention and behavioral expectation; in: Journal of Experimental Social Psychology, Vol. 21, No. 3, pp. 213-228

92. Wegner, D. M./Bargh, J. A. (1998): Control and Automaticity in Social Life; in: Gilbert, D./Fiske, S./Lindzey, G. (Eds.) The Handbook of Social Psychology, New York, pp. 446-496

93. Wegner, D.M./Wheatley, T. (1999): Apparent Mental Causation: Sources of the Experience of Will; in: American Psychologist, Vol. 54, No. 7, pp. 480-492

94. West, G.P. (2007): Collective Cognition: When Entrepreneurial Teams, Not Individuals Make Decisions; in: Entrepreneurship Theory and Practice, 31, No. 1 (2007), pp. 77-102

95. Wiersma, M.F./Bantel, K.A. (1992): Top Management Team Demography and Corporate Strategic Change; in: Academy of Management Journal, 35, No. 1 (1992), pp. 91 - 121

96. Wong, C. / Mullan, B. (2009): Predicting breakfast consumption: An application of the theory of planned behaviour and the investigation of past behaviour and executive function; in: British Journal of Health Psychology, Vol. 14, pp. 489-504 